\section{Hypersensitivity to Chironomid Larvae in a Nonatopic Patient: Safe Diagnosis Tools to Identify a Potent Allergen}

de las Vecillas L ${ }^{1}$, Bartolomé-Zavala B ${ }^{2}$, Asensio E ${ }^{3}$, San Segundo $\mathrm{D}^{3}$, Rodríguez $\mathrm{F}^{1}$, Montecchiani $\mathrm{V}^{1}$, Antón $\mathrm{E}^{1}$

${ }^{I}$ Allergy Service, Hospital Universitario Marqués de Valdecilla - IDIVAL, Santander, Cantabria, Spain

${ }^{2} R \& D$ Department, Roxall, Bilbao, Spain

${ }^{3}$ Immunology Service, Hospital Universitario Marqués de Valdecilla-IDIVAL, Santander, Cantabria, Spain

J Investig Allergol Clin Immunol 2018; Vol. 28(4): 259-260 doi: $10.18176 /$ jiaci.0250

Key words: Chironomus thummi. Basophil activation test. Chi t 1. Chironomid hemoglobin. IgE immunoblotting.

Palabras clave: Chironomus thummi. Test de activación de basófilos. Chi t 1. Hemoglobina de quironómido. IgE immunoblotting.

Red midge (Chironomus thummi thummi), an insect belonging to the Diptera order, is found worldwide, especially in wetlands $[1,2]$. The use of red midge larvae as fish food in factories and in pastimes such as fishing and keeping pets has increased human exposure to this insect [1]. The allergenic potential of this nonstinging midge is well-known and more likely to be observed in patients who are allergic to dust mites, crustaceans, or other arthropods owing to cross-reactivity $[1,3,4]$. Inhalation of red midge protein can cause symptoms such as urticaria, bronchospasm, nephrotic syndrome, and anaphylaxis [1,2,5-7]. Adverse systemic reactions to skin prick tests (SPTs) with these larvae have been reported [7]. Chironomid hemoglobin has been identified as the major allergen in this species, with a molecular weight of 15 to $16.6 \mathrm{kDa}$ (Chi t 1) [8].

A 27-year-old woman with no history of atopy reported rhinitis after 2 months of handling red midge larvae. Ten minutes after feeding her 2 puffer fish with $C$ thummi larvae, she developed rhinorrhea, congestion, sneezing, and nasal itching. The symptoms improved after leaving the room. However, some weeks later, the rhinitis worsened and was accompanied by red, watery eyes and palpebral angioedema. Finally, the patient presented rhinoconjunctivitis symptoms when she entered the room where the fish had been fed 12 hours earlier by another person. The clinical symptoms did not appear if the fish were not fed with the larvae, and she became asymptomatic when she moved house.

The patient was asymptomatic when she came to our clinic, 1 month after her last exposure to the culprit larvae. Previously, SPT was performed with commercial extracts of different allergen sources that can cause cross reactivity with $C$ thummi proteins $[1,3,4]$, as follows: Dermatophagoides pteronyssinus (100 UB/mL, ALK-Abelló, S.A.), shrimp (1 mg/mL, Bial-Aristegui), mussel (1 mg/mL, Bial-Aristegui), Anisakis simplex (2 mg/mL, ALK-Abelló, S.A.), common mosquito $(275 \mu \mathrm{g} / \mathrm{ml}$, Laboratorios LETI), and cockroach (325 $\mu \mathrm{g} / \mathrm{mL}$, Laboratorios LETI). The results were negative (wheal size $<3 \mathrm{~mm}$ )

Total IgE was 23.20 IU/L by ImmunoCAP (Thermo Fisher Scientific). Specific IgE levels (measured using the same technique) to the allergenic sources assayed in the SPT were negative $\left(<0.35 \mathrm{kU}_{\mathrm{A}} / \mathrm{L}\right)$.

Protein extract from freeze-dried pure $C$ thummi larvae (commercial fish food used by the patient [3F Frozen Fish Food]) were prepared by delipidization with acetone (4\% wt/vol), homogenization in PBS $100 \mathrm{mM}$ and $\mathrm{NaCl}$ $100 \mathrm{mM}(\mathrm{pH} 7.5)(5 \% \mathrm{wt} / \mathrm{vol})$ for 2 hours at $4^{\circ} \mathrm{C}$, dialyzation, and lyophilization [1]. Specific IgE against $C$ thummi larvae extract was $3.7 \mathrm{kU}_{\mathrm{A}} / \mathrm{L}$ by Enzyme AllergoSorbent Test (EAST; Specific IgE EIA kit HYTEC HYCOR Biomedical Ltd [9]). SDS-PAGE IgE-immunoblotting was carried out under reducing electrophoretic conditions (with 2-mercaptoethanol) using extracts from $C$ thummi larvae, D pteronyssinus, Penaeus monodon, Blatella germanica, and Periplaneta americana. IgE-binding bands were detected only with $C$ thummi larvae extract. A faint IgE-binding area of

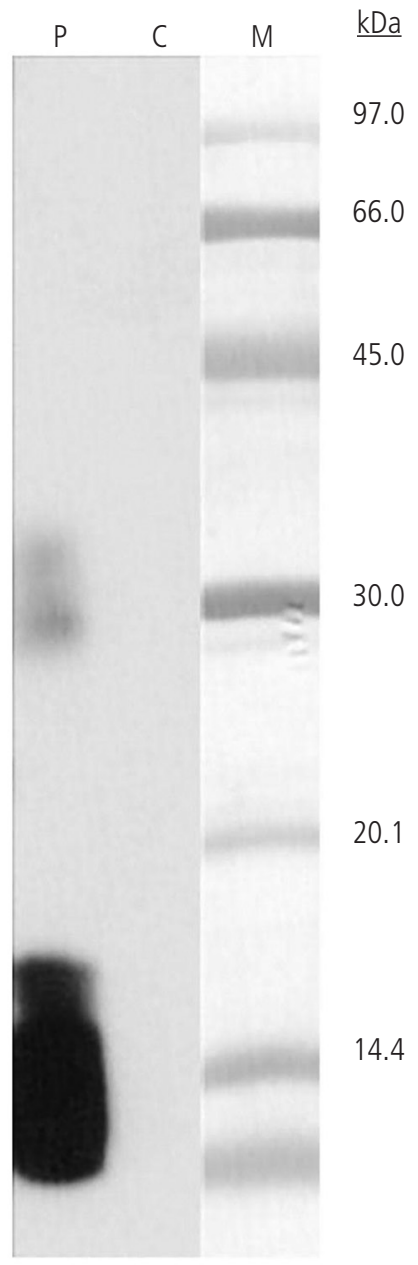

Figure. SDS-PAGE IgE-Immunoblotting with Chironomus thummi larvae extract under reducing electrophoretic conditions (with 2-mercaptoethanol). Lane P, patient serum; Lane C, control serum (pool of sera from nonatopic persons); Lane $\mathrm{M}$, molecular mass marker. 
approximately $30-32 \mathrm{kDa}$ and an intense one of approximately $17-10 \mathrm{kDa}$ were detected. The molecular mass of these areas matched those of the dimeric and monomeric forms of the chironomid hemoglobin, respectively (Figure) $[1,8]$.

A flow cytometry assay to determine the percentage of activated blood basophils that expressed the CD63 marker (basophil activation test) after in vitro stimulation with $C$ thummi larvae extract was performed as described in a previous publication [6]. Positive results (cut-off, 15\% CD63 ${ }^{+}$ basophils) were obtained with 2 of the 3 concentrations tested (19.3\% $\mathrm{CD}^{+} 3^{+}$basophils at $0.25 \mathrm{mg} / \mathrm{mL}$ and $2.5 \mathrm{mg} / \mathrm{mL}$ and $12.1 \%$ at $0.025 \mathrm{mg} / \mathrm{mL}$; baseline $\mathrm{CD}^{+} 3^{+}$basophils, $1.7 \%$; $\mathrm{CD}^{+} 3^{+}$basophils with anti-IgE, 33.9\%).

We report a case of allergy to $C$ thummi thummi larvae in a nonatopic patient who was sensitized to these larvae after a short exposure to low amounts of the allergenic source. Because an anaphylactic reaction during skin testing with C thummi larvae extracts has been reported, the use of in vitro tests such as specific IgE and the basophil activation test [6] have been proposed as safe, useful, and valid diagnostic tools.

The diagnosis was based on the clinical history and in vitro tests (specific IgE determination and BAT). Only avoidance induced clinical remission of the symptoms. In spite of the widespread domestic use of these larvae and the scarce number of reports of $C$ thummi allergy, our results highlight the high allergenic potential of this source, even in nonatopic individuals. Our results also support previously published evidence about the utility of in vitro testing to identify airborne allergenic sources. Given the high risk of airway involvement with skin testing and challenge testing [7], BAT and IgEimmunoblotting were shown to be reliable diagnosis tools.

\section{Acknowledgments}

We are very grateful to the nursing team of Hospital Universitario Marqués de Valdecilla Allergy Service for their help in processing the serum sample and for performing skin testing. We are especially grateful to Marian Salcines Monar. Similarly, we are grateful to Begoña Zabala and Dani López for their help with the EAST and immunoblotting assays

\section{Funding}

The authors declare that no funding was received for the present study.

\section{Conflicts of Interest}

The authors declare that they have no conflicts of interest.

\section{Previous Presentation}

This article was presented as a poster during the Simposio Internacional de Vía Aérea Única, October 2015, Sevilla, Spain (SEAIC annual meeting).

\section{References}

1. Ballestero SC, De Barrio M, Baeza ML, Sotés MR. Allergy to chironomid larvae (red midge larvae) in non professional handlers of fish food. J Investig Allergol Clin Immunol. 2006;16(1):63.

2. Arce JM, Villajos IS, Iraola V, Carnés J, Caldas EF. Occupational allergy to aquarium fish food: red midge larva, freshwater shrimp, and earthworm. A clinical and immunological study. J Investig Allergol Clin Immunol. 2013;23(7):462-70.

3. Pascual CY, Crespo JF, San Martin S, Ornia N, Ortega N, Caballero $T$, et al. Cross-reactivity between lgE-binding proteins from Anisakis, German cockroach, and chironomids. Allergy. 1997;52(5):514-20.

4. Nagano T, Ohta N, Okano M, Ono T, Masuda Y. Analysis of antigenic determinants shared by two different allergens recognized by human $T$ cells: house dust mite (Dermatophagoides pteronyssinus) and chironomid midge (Chironomus yoshimatsui). Allergy. 1992;47(5):554-9.

5. Moneret-Vautrin DA, Bertheau JM. IgE-dependent nephrotic syndrome due to inhalation of chironomid larvae. Allergy. 2005;60(2):265-6.

6. Cabrera-Freitag P, Ferrer M, Martínez R, Javaloyes G, Sanz ML. The basophil activation test as a promising diagnostic tool in hypersensitivity to chironomid larvae. J Investig Allergol Clin Immunol. 2011;21(2):153-61.

7. Nguyen M, Paradis L, Des Roches A, Primeau MN, Paradis J. Adverse reactions resulting from skin testing in the diagnosis of red grubs (Chiromides) allergy. Allergy. 2007;62(12):14701.

8. Liebers $V$, Baur X. Chironomidae haemoglobin Chit Icharacterization of an important inhalant allergen. Clin Experiment All. 1994;24(2):100-8.

9. Nolte $H$, DuBuske LM. Performance characteristics of a new automated enzyme immunoassay for the measurement of allergen-specific IgE. Summary of the probability outcomes comparing results of allergen skin testing to results obtained with the HYTEC system and CAP system. Ann Allergy Asthma Immunol. 1997;79:27-34.

Manuscript received July 4, 2017; accepted for publication March 2, 2018.

Leticia de las Vecillas

E-mail: leticia.delasveci@gmail.com 